\title{
EQUILÍBRIO, TERMODINÂMICA E REUSO DE FILMES DE QUITOSANA MODIFICADOS COM ÍONS VANÁDIO NA ADSORÇÃO DO CORANTE REATIVO PRETO 5
}

\author{
D. A. S. RODRIGUES ${ }^{1}$, D. D. R. GRÜNDMAM ${ }^{1}$, B. S. FARIAS ${ }^{1}$, J. M. MOURA ${ }^{1}$, T. R. S. \\ CADAVAL JR. ${ }^{1}$, L. A. A. PINTO ${ }^{1}$ \\ ${ }^{1}$ Universidade Federal de Rio Grande, Escola de Química e Alimentos \\ e-mail: denys.asr@gmail.com
}

\begin{abstract}
RESUMO
Neste trabalho foram produzidos filmes de quitosana modificados com íons vanádio para a adsorção do corante RB5. Os filmes foram preparados a partir de quitosana obtidas de resíduos de camarão, e reticulados através da adsorção de íons vanádio. Os filmes modificados de quitosana (FMQ) apresentaram espessura, alongamento e tensão de ruptura similares aos de filme puros de quitosana. A fim de avaliar o comportamento dos filmes modificados na operação de adsorção, estes foram aplicados na remoção do corante (RB5) em meio aquoso. Os ensaios de equilíbrio foram realizados em batelada e sob diferentes temperaturas. Os modelos de isoterma de Freundlich e de Langmuir foram ajustados aos dados experimentais e os parâmetros termodinâmicos avaliados. O modelo que melhor se ajustou aos dados experimentais foi o de Freundlich. A capacidade máxima de adsorção foi obtida a $298 \mathrm{~K}$. O processo de adsorção foi exotérmico, espontâneo, favorável e predominantemente entálpico. Os FMQ foram reutilizados por cinco ciclos mantendo capacidade de adsorção dentro de valores interessantes.
\end{abstract}

\section{INTRODUÇÃO}

A preocupação com questões ambientais vem crescendo gradativamente no Brasil. As indústrias têxteis constituem um dos grandes passivos ambientais, pois causa graves problemas gerados pelo descarte de altas cargas de despejos poluidores, com elevado teor de contaminação (CAMEL e BERMOND, 1998).

Os rejeitos desse tipo de indústria, se não tratados adequadamente, podem se tornar um fator preocupante quando despejados em mananciais. Os principais contaminantes da indústria têxtil são os corantes reativos, que por sua vez são compostos tóxicos e não biodegradáveis que afetam principalmente a vida aquática (SILVEIRA NETA et al., 2012).

Existe cerca de 10.000 diferentes tipos de corantes e pigmentos, sendo que $8 \times 10^{5}$ toneladas são consumidos anualmente em todo o mundo e aproximadamente $30 \%$ desse valor é consumido no Brasil (SILVEIRA NETA et al., 2012). Estima-se que a formação de efluente alcance o valor de $15 \%$ dessa quantidade (CRINI e BADOT, 2008).

A remoção dessas espécies do meio aquoso é extremamente dificultada por suas elevadas solubilidades, e principalmente devido aos corantes não pertencerem às mesmas classes de compostos químicos e apresentarem grupos funcionais diferenciados (FUNGARO et al., 2009). 
Existem diversos processos para remover esse tipo de contaminante de meios aquosos, dentre eles, a adsorção é um dos métodos mais comumente utilizado. Atualmente uma série de adsorventes tem sido estudados, dentre eles destacam-se os provenientes de fontes renováveis (KUNZ at al., 2006). Um adsorvente que vem ganhando seu espaço e se tornado cada vez mais promissor é a quitosana, uma forma parcialmente ou totalmente desacetilada da quitina. A quitina é constituída por unidades de $\beta(1 \rightarrow 4)$-2-amino-2-desoxi-D-glicopiranose e $\quad \beta(1 \rightarrow 4)$-2-acetamido-2-desoxiglicopiranose. É encontrada em abundância na natureza e tem como principais fontes naturais às carapaças de crustáceos (caranguejo, camarão, lagosta), sendo também encontrada em insetos, moluscos e na parede celular de fungos (RINAUDO, 2006).

A quitosana é biologicamente inerte assim como a quitina apresenta características importantes como biocompatibilidade, biodegradabilidade, hidrofilicidade, propriedades bactericidas e bioatividade, além de não apresentar toxidade tornando-a propicia na utilização no processo de adsorção (SILVEIRA NETA et al., 2012).

A utilização de quitosana como adsorvente na forma de pó ou em flocos é muito frequente. Porém, nestas formas a quitosana apresenta desvantagens como a necessidade de centrifugação ou filtração para separação após a adsorção. Esses problemas são minimizados realizando modificações estruturais tais como a utilização de filmes de quitosana capazes de serem separados da solução por um simples gradeamento. Entretanto, existe a necessidade de modificações químicas na estrutura dos filmes a fim de possibilitar o reuso do adsorvente (RINAUDO, 2006).

As condições de equilíbrio e termodinâmica são importantes no correto dimensionamento da operação de adsorção em um determinado processo. (KAVITHA e
NAMASIVAYAMB, 2008). Assim os estudos de isotermas de equilíbrio fornecem informações relativas às interações intermoleculares entre $\mathrm{o}$ adsorvente $\mathrm{e}$ adsorbato e as isotermas de adsorção são afetadas pelos parâmetros de concentração de adsorbato, volume de adsorbato e massa de adsorvente (CRINI e BADOT, 2008; GUIBAL, 2004).

A determinação dos parâmetros termodinâmicos: variação da energia livre de Gibbs $\left(\Delta G^{\circ}\right)$, variação de entalpia de adsorção $\left(\Delta H^{\circ}\right)$ e a variação de entropia de adsorção $\left(\Delta S^{\circ}\right)$ são importantes, pois denotam características sobre as energias envolvidas no sistema. Os cálculos destes parâmetros indicam se o processo é espontâneo, endotérmico ou exotérmico e fornecem informações sobre a variação da desordem do sistema (ELWAKEEL, 2009).

O objetivo deste trabalho foi obter filmes de quitosana modificados com íons de vanádio, realizar estudos de equilíbrio, verificar o ajuste dos modelos e determinar os parâmetros termodinâmicos de adsorção do corante RB5 por FMQ. Os ensaios de equilíbrio foram realizados em diferentes temperaturas $(298,308,318$ e $328 \mathrm{~K})$ e os modelos de Langmuir e Freundlich utilizados para determinar os parâmetros de equilíbrio. Para o estudo da reutilização dos filmes, foram testados diferentes eluentes em diferentes concentrações.

\section{MATERIAL E MÉTODOS}

\subsection{Extração da quitina}

A extração da quitina foi realizada a partir de resíduos de camarão rosa (Penaeus brasiliensis), através dos tratamentos químicos sequenciais de desmineralização, desproteinização e desodorização, para a eliminação de carboidratos, proteínas e pigmentos, respectivamente (WESKA et al., 2007). 
Ao final, a quitina foi seca a $80^{\circ} \mathrm{C}$ durante $4 \mathrm{~h}$ em um secador de bandejas, e moídas (moinho de facas, Wiley 3, Swedesboro, NJ).

\subsection{Produção da quitosana}

A quitosana foi preparada através da reação de desacetilação alcalina da quitina. A reação foi realizada utilizando uma solução de $\mathrm{NaOH} 0,45 \mathrm{~kg} \mathrm{~L}^{-1}$ a uma temperatura de aproximadamente $135^{\circ} \mathrm{C}$ por $4 \mathrm{~h}$. Esta foi realizada em reator de aço inoxidável com capacidade para $4 \mathrm{~L}$ de solução, com agitação e aquecimento elétrico.

Para a purificação foi utilizado solução de ácido acético $(1 \% \mathrm{v} / \mathrm{v})$ para dissolver a quitosana. A solução foi centrifugada (Sigma 6-15, D-37520, Alemanha) a 6600×g durante 30 min, para a retirada do material não dissolvido. A seguir foi feita a precipitação da quitosana elevando o pH a 12,5 com a adição de solução de hidróxido de sódio ( $8 \%$ p/v), e após esta foi neutralizada com solução de ácido acético $1 \% \quad(\mathrm{v} / \mathrm{v})$. A solução foi centrifugada para retirada dos reagentes, obtendo-se a pasta de quitosana. Esta foi seca em secador de leito de jorro, onde as condições de operação utilizadas foram segundo Dotto et al. (2011), com temperatura de estrada de ar de secagem de $90^{\circ} \mathrm{C}$, a concentração da pasta de quitosana de $4 \%$ $(\mathrm{p} / \mathrm{p})$ e taxa de alimentação de pasta de 0,18 $\mathrm{kg}_{\text {pasta }} \mathrm{kg}^{-1}$ inerte $\mathrm{h}^{-1}$.

\subsection{Caracterização da quitosana}

\subsubsection{Massa Molar Média Viscosimétrica (MM)}

Para a determinação da massa molar média viscosimétrica foram preparadas soluções diluídas do biopolímero com solução de ácido acético $0,1 \mathrm{~mol} \mathrm{~L}^{-1}$ e cloreto de sódio $0,2 \mathrm{~mol} \mathrm{~L}^{-1}$ nas concentrações de quitosana de 0,$001 ; 0,003 ; 0,006 ; 0,009 ; 0,012 \mathrm{~g} \mathrm{~mL}^{-1}$. As medidas viscosimétricas das amostras de quitosana foram realizadas em viscosímetro capilar Cannon-Fensk (Schott Geraete, GMBH - D65719, Alemanha), à temperatura de $25,0 \pm 0,1^{\circ} \mathrm{C}$.

A viscosidade intrínseca $[\eta]$ foi estimada pelo ajuste da equação de Huggins (Equação 1) aos resultados obtidos.

$$
\frac{\eta_{S P}}{c}=[\eta]+k \cdot[\eta]^{2} \cdot c
$$

sendo $\eta_{s p} / c$ a viscosidade reduzida $\left(\mathrm{mL} \mathrm{g}^{-1}\right)$, $\eta_{s p}$ a relação entre as viscosidades do polímero em solução e do solvente, $c$ a concentração da solução $\left(\mathrm{g} \mathrm{mL}^{-1}\right)$ e $k$ uma constante válida para cada polímero, conforme Alsarra et al. (2002).

A massa molar média viscosimétrica (MM) da quitosana foi calculada a partir do valor da viscosidade intrínseca usando a equação de Mark-Houwink-Sakurada (Equação 2), citada por Roberts e Domszy (1982).

$[\eta]=K(M M)^{\alpha}$

em que $K=1,81 \times 10^{-3} \mathrm{~mL} \mathrm{~g}^{-1}$ e $\alpha=0,93$ são constantes que dependem do sistema solvente-polímero (KUMAR, 2000; GALED et al., 2002; CERVERA et al., 2004).

\subsubsection{Grau de desacetilação (GD)}

A determinação do grau de desacetilação das amostras de quitosana foi pelo método de titulação potenciométrica linear. Esta análise foi realizada dissolvendo $0,25 \mathrm{~g}$ de quitosana em $20 \mathrm{~mL}$ de solução de

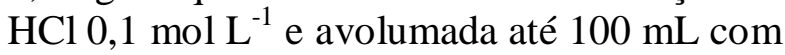
água destilada. $\mathrm{O} \mathrm{pH}$ da solução foi ajustado em aproximadamente 2,0 com solução padrão de $\mathrm{NaOH} 0,1 \mathrm{~mol} \mathrm{~L}^{-1}$, e foi medido com pHmetro (MB10-Marte-Brasil) sob agitação constante à $600 \mathrm{rpm}$ utilizando um agitador magnético (FISATOM 752A, Brasil), sendo considerado este, o ponto inicial da titulação. A titulação prosseguiu até a solução de 
quitosana alcançar o $\mathrm{pH}$ de aproximadamente 6,0 (faixa de não protonação da quitosana).

Um valor de $f(x)$ correspondente ao volume de $\mathrm{NaOH}$ utilizado é calculado utilizando a Equação 3.

$$
f(x)=\left(\frac{V_{0}+V}{N_{B}}\right) \cdot\left(\left[H^{+}\right]-\left[O H^{-}\right]\right)
$$

sendo: $V_{0}$ o volume de solução de quitosana $(\mathrm{mL}), V$ o volume de solução de $\mathrm{NaOH}$ utilizado na titulação $(\mathrm{mL}), N_{B}$ a concentração de solução de $\mathrm{NaOH}$ (meq L $\mathrm{L}^{-1}$ ); $\left[H^{+}\right]$a concentração de $\mathrm{H}^{+}$(meq $\mathrm{L}^{-1}$ ); e $\left[\mathrm{OH}^{-}\right]$a concentração de $\mathrm{OH}^{-}\left(\right.$meq L $\left.{ }^{-1}\right)$.

A curva de titulação linear foi obtida plotando um gráfico de $f(x)$ em função do volume corresponde de solução de $\mathrm{NaOH}$. $\mathrm{O}$ volume de solução de $\mathrm{NaOH}$ ao fim da titulação, $V_{e}$, foi calculado extrapolando a curva de titulação linear em função do volume de solução de $\mathrm{NaOH}$ adicionado. $\mathrm{O}$ grau de desacetilação da amostra de quitosana foi calculado utilizando a Equação 4:

$$
G D(\%)=\frac{\varphi}{[(W-161 \varphi) / 204+\varphi]} \cdot 100
$$

sendo:

$$
\varphi=\frac{\left(N_{A} V_{A}-N_{B} V_{e}\right)}{1000}
$$

onde, $N_{A}$ é a concentração de solução de $\mathrm{HCl}$ (meq $\mathrm{L}^{-1}$ ), $V_{A}$ o volume de solução de $\mathrm{HCl}$ $(\mathrm{mL}), N_{B}$ a concentração de solução de $\mathrm{NaOH}$ (meq $\left.\mathrm{L}^{-1}\right), V_{e}$ o volume de solução de $\mathrm{NaOH}$ ao fim da titulação (mL) e $W$ a massa de quitosana (g) (TAN at al., 1998; JIANG at al., 2003).

\subsection{Elaboração dos FQM}

Os filmes de quitosana foram preparados segundo a técnica casting, de acordo com o seguinte procedimento: foi utilizado $1,6 \mathrm{~g}$ de quitosana dissolvida em solução de ácido acético $0,1 \mathrm{~mol} \mathrm{~L}^{-1}$, sob agitação constante de $300 \mathrm{rpm}$ a temperatura de $25 \pm 1^{\circ} \mathrm{C}$ durante $24 \mathrm{~h}$. Após, $50 \mathrm{~mL}$ da solução formadora de filme foi vertida em placa de petri, e levada a estufa com circulação forçada de ar a $40^{\circ} \mathrm{C}$ durante $24 \mathrm{~h}$ para evaporação do solvente. Após, os filmes foram removidos das placas e levados ao dessecador por $48 \mathrm{~h}$ antes da caracterização e dos experimentos de adsorção.

Para a modificação do filme com íons de vanádio, o filme de quitosana foi cortado em tiras de área igual a $1 \mathrm{~cm}^{2}$. Amostras de 2 $\mathrm{g}$ destes filmes foram adicionadas a uma solução de vanádio de $100 \mathrm{mg} \mathrm{L} \mathrm{L}^{-1}$, previamente preparados e o $\mathrm{pH}$ da solução ajustado em 6,0 a $50 \mathrm{rpm}$ e temperatura ambiente.

\subsection{Caracterização dos FMQ}

\subsubsection{Espessura}

A espessura média foi calculada a partir de dez medidas aleatórias na superfície do filme com a utilização de um paquímetro digital (Mitutoya Corp, MDC-25S, Japão) (FERREIRA et al. 2009).

\subsubsection{Tensão de Ruptura e Alongamento}

Para determinar as propriedades mecânicas, o FMQ foi cortado em formato retangular com $100 \mathrm{~mm}$ de comprimento e 25 $\mathrm{mm}$ de largura, e foi utilizado um texturômetro (Stable Microsistems SMD, TA.XP2i, Reino Unido) de acordo com o método D00882-00 (ASTM, 2000b), com células de cargas de $50 \mathrm{~N}$. Para realização dos ensaios, adotou-se uma distância inicial entre as extremidades, de $50 \mathrm{~mm}$ (ASTM. Método: E00996-00). 


\subsection{Especificações do corante RB5}

O corante têxtil reativo preto 5 (RB5) (95\% de pureza, massa molar 991,8 $\mathrm{g} \mathrm{mol}^{-1}$; $\lambda_{\max }=597 \mathrm{~nm}$, índice de cor 20505) foi fornecido pela Sigma-Aldrich, Brasil, e utilizado sem purificação adicional.

\subsection{Experimentos de Adsorção}

As soluções de RB5 (1,00 $\left.\mathrm{g} \mathrm{L}^{-1}\right)$ foram preparadas, e o $\mathrm{pH}$ foi ajustado a 4,0, com solução tampão fosfato dissódico/ácido cítrico $0,1 \mathrm{~mol} \mathrm{~L}^{-1}$. Os ensaios foram realizados em batelada sob taxa de agitação de 100 rpm, até o equilíbrio. Foram obtidas as isotermas de equilíbrio, em temperaturas de 298, 308, 318 e $328 \mathrm{~K}$ e concentrações de corante de 50 a $500 \mathrm{mg} \mathrm{L}^{-1}$.

Em todos os testes acima, a concentração RB5 foi determinada por espectrofotometria (Biospectro, SP-22, Brasil). Os experimentos foram realizados em replicata $(n=2)$.

\subsubsection{Experimentos de equilíbrio}

Foram preparados $200 \mathrm{~mL}$ de soluções do corante RB5 em seis diferentes concentrações $(50,100,200,300,400$ e 500 $\mathrm{mg} \mathrm{L}^{-1}$ ), e tamponadas com solução fosfato dissódico/ácido cítrico a $\mathrm{pH} 4,0$. Os filmes com dimensões de $1 \mathrm{~cm} \times 1 \mathrm{~cm}$ foram adicionados às soluções contendo corante. As soluções foram colocadas em frascos de 500 $\mathrm{mL}$ e agitadas à $100 \mathrm{rpm}$ usando um agitador termostatizado (FANEM315 SE, Brasil) até o equilíbrio. Após, determinou-se a quantidade de corante remanescente na fase líquida por espectrofotometria (Quimis, Q108, Brasil). A capacidade de adsorção no equilíbrio $\left(q_{e}\right)$ foi determinada pela Equação 6:

$q_{e}=\frac{C_{0}-C_{e}}{m} V$

sendo $C_{0}$ e $C_{e}$ as concentrações inicial e no equilíbrio na fase líquida $\left(\mathrm{mg} \mathrm{L}^{-1}\right)$, respectivamente, $m$ a massa de adsorvente $(\mathrm{g})$ e $V$ o volume da solução (L).

A fim de estabelecer a correlação mais adequada para as curvas de equilíbrio, foram utilizados os modelos de Langmuir (Equação 7) e de Freundlich (Equação 8) (ZHANG at al., 2010)

$$
q_{e}=\frac{q_{m} k_{L} C_{e}}{1+k_{L} C_{e}}
$$

sendo $q_{m}$ a máxima capacidade de adsorção na monocamada $\left(\mathrm{mg} \mathrm{g}^{-1}\right)$, e $k_{L}$ a constante de Langmuir $\left(\mathrm{L} \mathrm{mg}^{-1}\right)$.

$$
q_{e}=k_{F} C_{e}^{1 / n}
$$

sendo $k_{F}$ a constante de Freundlich $\left(\left(\mathrm{mg} \mathrm{g}^{-}\right.\right.$ $\left.\left.{ }^{1}\right)\left(\mathrm{L} \mathrm{mg}^{-1}\right)^{1 / \mathrm{n}}\right)$ e $1 / n$ o fator de heterogeneidade.

Os parâmetros das isotermas foram determinados por regressão não linear utilizando o método de estimação QuasiNewton (Statistica 7.0 Statsoft, EUA). A qualidade do ajuste foi verificada de acordo com o coeficiente de determinação $\left(\mathrm{R}^{2}\right)$ e o erro médio relativo (EMR).

\subsubsection{Parâmetros termodinâmicos}

As variações da energia livre de Gibbs $\left(\Delta G^{\circ}\right)$, da entalpia $\left(\Delta H^{\circ}\right)$ e da entropia $(\Delta S$ ${ }^{\circ}$ ) foram estimadas a partir das Equações 9, 10 e 11, respectivamente: (MILONJIC, 2007)

$$
\begin{aligned}
& \Delta G^{\circ}=-R T \ln \left(\rho_{w} K_{D}\right) \\
& \Delta G^{\circ}=\Delta H^{\circ}-T \Delta S^{\circ} \\
& \ln \left(\rho_{w} K_{D}\right)=\frac{\Delta S}{R}-\frac{\Delta H}{R T}
\end{aligned}
$$


sendo $R$ a constante universal dos gases $(\mathrm{kJ}$ $\left.\mathrm{mol}^{-1} \mathrm{~K}^{-1}\right), T$ é a temperatura $(\mathrm{K}), \rho_{w}$ a massa específica da água $\left(\mathrm{mg} \mathrm{L}^{-1}\right)$ contido em um volume de $1 \mathrm{~L}$ e $K_{D}$ a constante de equilíbrio termodinâmico $\left(\mathrm{L} \mathrm{mg}^{-1}\right)$. A constante $K_{D}$ foi estimada a partir da linearização da isoterma de melhor ajuste (CARDOSO et al., 2011).

\subsection{Dessorção e Reuso do adsorvente}

Para o estudo da dessorção foram realizados quatro diferentes tratamentos com a utilização de dois eluentes $(\mathrm{NaOH}$ e $\left.\mathrm{NH}_{4} \mathrm{OH}\right)$ em duas concentração cada $(0,001 \mathrm{e}$ 0,01 mol L ${ }^{-1}$ ) (CRINI e BADOT, 2008; RÊGO et al., 2013). Os filmes após serem utilizados como adsorventes, foram submersos nas diferentes soluções eluentes. Após $24 \mathrm{~h}$ as concentrações finais de corante presente nas soluções foram determinadas.

Após definir o melhor eluente, foram realizados cinco ciclos de adsorção/dessorção, onde foram determinados os percentuais de adsorção, bem como os de dessorção, utilizando o eluente que apresentou o melhor percentual de remoção.

\section{RESULTADOS E DISCUÇÃO}

\subsection{Características da quitina}

As amostras de quitina apresentaram a seguinte composição centesimal depois das etapas de desmineralização, desproteinização, desodorização e secagem $(\% \mathrm{p} / \mathrm{p}$, em base úmida): $1,1 \pm 0,2 \%$ de cinzas, $0,2 \pm 0,1 \%$ de proteína e 6,0 $\pm 1,0 \%$ de teor de umidade. Resultados semelhantes foram encontrados Weska et al. (2007).

\subsection{Características da quitosana}

A quitosana produzida apresentou as seguintes características de massa molar e grau de desacetilação após as etapas de desacetilação e purificação, 101 kDa e 95,9\%, respectivamente.

\subsection{Características do FMQ}

O FMQ produzido apresentou os valores de $66 \mu \mathrm{m}, 27,2 \mathrm{MPa}$ e $8,7 \%$, para a espessura, tensão de ruptura e alongamento, respectivamente. Resultados semelhantes foram encontrados para os filmes de quitosana por Dotto et al. (2013).

\subsection{Isotermas de equilíbrio e termodinâmica}

As curvas de equilíbrio de adsorção foram constituídas a fim de verificar o efeito da temperatura na capacidade de adsorção dos filmes modificados. A Figura 1 apresenta o gráfico das curvas de equilíbrio em diferentes temperaturas.

Figura 1. Curva de equilíbrio da adsorção do RB5 por FMQ.

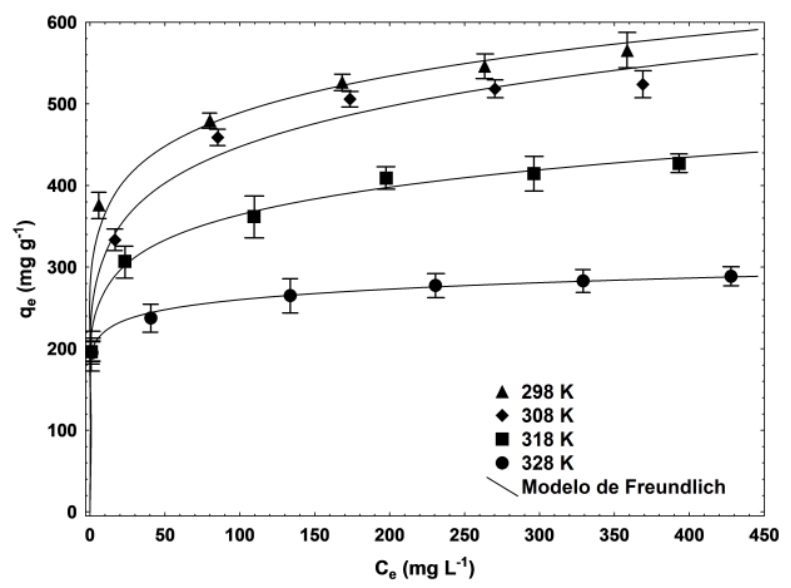

Observa-se na Figura 1 que para o FMQ a isoterma foi caracterizada como tipo I. Este tipo de isoterma apresenta um limite na capacidade de adsorção que corresponde à formação de uma camada monomolecular em adsorventes não porosos ou microporosos (BLÁZQUEZ et al., 2010). Além disso, a Figura 1 mostra que a capacidade de adsorção aumentou com a diminuição da temperatura, sendo que os valores máximos foram obtidos a 298 K (DOTTO e PINTO, 2011).

Os parâmetros de equilíbrio para a adsorção de RB5 por FMQ dos modelos de Langmuir (Equação 7) e Freundlich (Equação 8) estão apresentados na Tabela 1. 
Tabela 1. Parâmetros de equilíbrio para a adsorção de RB5 sobre o filme modificado de quitosana.

\begin{tabular}{ccccc}
\hline \multirow{2}{*}{$\mathrm{T}(\mathrm{K})$} & \multicolumn{5}{c}{ Langmuir } \\
\cline { 2 - 5 } & $k_{L}\left(\mathrm{~L} \mathrm{mg}^{-1}\right)$ & $q_{m}\left(\mathrm{mg} \mathrm{g}^{-1}\right)$ & $\mathrm{R}^{2}$ & EMR (\%) \\
\hline 298 & 1,92 & 511,80 & 0,91 & 11,05 \\
308 & 0,91 & 479,80 & 0,88 & 12,50 \\
318 & 0,96 & 390,40 & 0,89 & 9,02 \\
328 & 1,90 & 271,90 & 0,87 & 4,70 \\
\hline \multirow{2}{*}{$\mathrm{T}(\mathrm{K})$} & $k_{F}\left(\mathrm{mg} \mathrm{g}^{-1}\right)\left(\mathrm{mg} \mathrm{L}^{-1}\right)^{-1 / \mathrm{n}} \mathrm{F}$ & Freundlich \\
\hline 298 & 273,10 & 7,90 & 0,98 & EMR (\%) \\
308 & 222,74 & 6,60 & 0,99 & 3,80 \\
318 & 201,76 & 7,80 & 0,99 & 1,74 \\
328 & 188,47 & 14,30 & 0,99 & 0,93 \\
\hline
\end{tabular}

Pode-se observar na Tabela 1 que altos valores de coeficiente de determinação $\left(\mathrm{R}^{2}>0,98\right)$ e os baixos valores do erro médio relativo $(\mathrm{EMR}<5,00 \%)$ mostram que o modelo de Freundlich foi o mais adequado para representar a adsorção do RB5 por FMQ.
A constante de equilíbrio termodinâmico $\left(K_{D}\right)$, a energia livre de Gibbs $\left(\Delta G^{\circ}\right)$, a variação de entalpia $\left(\Delta H^{\circ}\right)$ e a variação de entropia $\left(\Delta \mathrm{S}^{\circ}\right)$ foram determinados, e os resultados estão apresentados na Tabela 2 .

Tabela 2. Parâmetros termodinâmicos para a adsorção do RB5 em FMQ.

\begin{tabular}{ccccc}
\hline & \multicolumn{4}{c}{ Temperatura $(\mathrm{K})$} \\
\cline { 2 - 5 } & 298 & 308 & 318 & 328 \\
\hline$K_{D}\left(\mathrm{~L} \mathrm{~g}^{-1}\right)$ & $273,10 \pm 1.03$ & $222,74 \pm 0.98$ & $201,76 \pm 1.50$ & $188,47 \pm 1.09$ \\
$\Delta G^{\circ}\left(\mathrm{kJ} \mathrm{mol}^{-1}\right)$ & $-31,00 \pm 0,02$ & $-31,52 \pm 0,02$ & $-32.28 \pm 0,01$ & $-33,11 \pm 0,02$ \\
$\Delta H^{\circ}\left(\mathrm{kJ} \mathrm{mol}^{-1}\right)$ & \multicolumn{4}{c}{$-9,91 \pm 1.35$} \\
$\Delta S^{\circ}\left(\mathrm{kJ} \mathrm{mol}^{-1} \mathrm{~K}^{-1}\right)$ & \multicolumn{3}{c}{$0,0705 \pm 0.01$} \\
\hline
\end{tabular}

Os valores de $K_{D}$ (Tabela 2) aumentaram com a diminuição da temperatura, confirmando que a adsorção de RB5 por o FMQ foi favorecida a $298 \mathrm{~K}$. Os valores negativos de $\Delta G^{\circ}$ indicam que a adsorção do RB5 foi um processo espontâneo e energeticamente favorável (LIU, 2010). Os valores negativos de $\Delta H^{\circ}$ indicam um processo exotérmico. Além disso, sua magnitude indica a ocorrência de adsorção física devido às interações eletrostáticas (CRINI e BADOT, 2008; LIU, 2010; WANG, 2010). O valor de $\Delta S^{\circ}$ foi positivo, sugerindo o aumento da aleatoriedade na interface sólido/solução devido às interações existentes entre adsorvente e adsorbato.

\subsection{Dessorção e Reuso}

Para a dessorção do RB5 do FMQ, dois eluentes foram testados $\left(\mathrm{NaOH}\right.$ e $\mathrm{NH}_{4} \mathrm{OH}$ em diferentes concentrações). A Tabela 3 apresenta os percentuais de dessorção obtidos em cada um dos tratamentos realizados.

Tabela 3. Resultados da dessorção do RB5 do filme modificado de quitosana.

\begin{tabular}{ccc}
\hline Eluentes & $\begin{array}{c}\text { Concentração } \\
\left(\mathrm{mol} \mathrm{L}^{-1}\right)\end{array}$ & $\begin{array}{c}\text { Dessorção } \\
(\%)\end{array}$ \\
\hline \multirow{2}{*}{$\mathrm{NaOH}$} & 0,001 & $70,8 \pm 2,4$ \\
& 0,01 & $91,5 \pm 1,6$ \\
$\mathrm{NH}_{4} \mathrm{OH}$ & 0,001 & $88,9 \pm 1,2$ \\
& 0,01 & $96,0 \pm 1,4$ \\
\hline
\end{tabular}


Observa-se na Tabela 3, que para a dessorção do RB5 dos FMQ o eluente mais adequado foi o $\mathrm{NH}_{4} \mathrm{OH} 0,01 \mathrm{~mol} \mathrm{~L}^{-1}$.

Este resultado confirma o mecanismo de interação eletrostática, uma vez que esta interação foi rompida com a solução de $\mathrm{NH}_{4} \mathrm{OH}$.

Após definir o eluente apropriado foram realizados cinco ciclos de adsorção/dessorção do FMQ, para avaliar se o mesmo poderia ser reutilizado. A Figura 2 apresenta os percentuais de remoção de adsorção/dessorção em cada ciclo de reuso.

Figura 2. Gráfico dos percentuais de remoção dos ciclos de reuso (adsorção/dessorção).

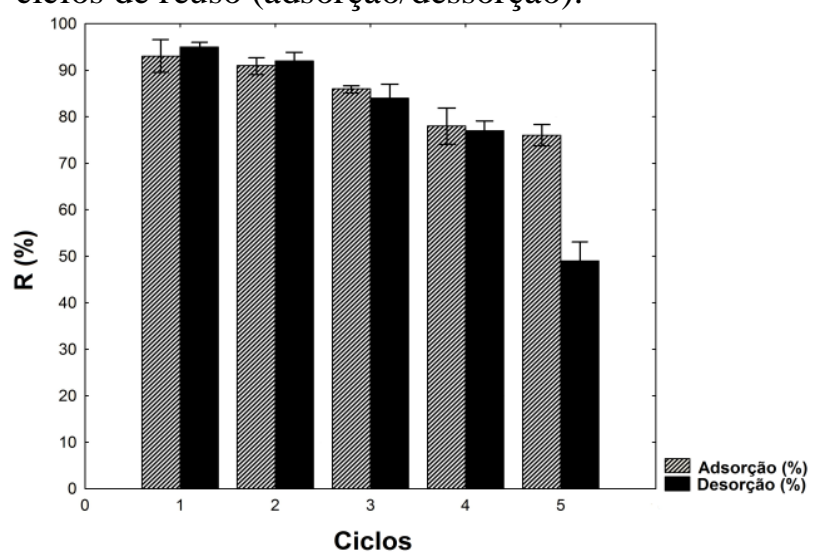

Pode-se observar na Figura 2 que o FMQ apresentou um bom desempenho quanto a sua reutilização, pois após cinco ciclos de adsorção/dessorção estes perderam aproximadamente $20 \%$ da sua capacidade de remoção. Pôde-se observar também que além da pequena redução no percentual de remoção do RB5 dos filmes, estes mantiveram sua integridade física até o quinto ciclo.

\section{CONCLUSÃO}

Neste trabalho foi obtido experimentalmente as isotermas de adsorção e ajustados os modelos de isotermas, para determinação dos parâmetros termodinâmicos de adsorção do corante têxtil reativo preto 5 (RB5) por filmes modificados de quitosana com íon de vanádio (FMQ). O modelo de Freundlich foi adequado para representar os dados de equilíbrio, e a capacidade máxima de adsorção foi de $360 \mathrm{mg} \mathrm{g}^{-1}$ para FMQ, a 298 K. Em relação aos parâmetros termodinâmicos, o processo foi exotérmico, espontâneo, favorável e controlado pela entalpia. O FMQ foi um adsorvente adequado para RB5, apresentando uma boa capacidade de adsorção e pôde ser reutilizado por cinco ciclos de adsorção/dessorção.

\section{REFERÊNCIAS}

ALSARRA, I. A.; BETIGERI, S. S.; ZHANG, H.; EVANS, B. A.; NEAU, S. H. Molecular weight and degree of deacetylation effects on lipase-loaded chitosan bead characteristics. Biomaterials, v. 23, p. 36373644, 2002.

ASTM. Standard methods of water vapor transmission of materials. Método: E0099600. In: ASTM annual book of ASTM standards (pp. 907-914). Philadelphia: American Society for Testing and Materials.

BLÁZQUEZ, G.; CALERO, M.; HERNÁINZ, F.; TENORIO, G.; MARTÍNLARA, M. A. Equilibrium biosorption of lead (II) from aqueous solutions by solid waste from olive-oil production. Chemical Engineering Journal, v. 160, p. 615-622, 2010.

CAMEL, V.; BERMOND, A. The use of ozone and associated oxidation processes in drinking water tratament. Water Research, v. 32, p. 3208-3222, 1998.

CARDOSO, N. F.; LIMA, E. C.; CALVETE, T.; PINTO, I. S.; AMAVISCA, C. V.; FERNANDES, T. H. M.; PINTO, R. B.; ALENCAR, W. S. Application of Aqai Stalks As Biosorbents for the Removal of the Dyes Reactive Black 5 and Reactive Orange 16 
from Aqueous Solution. Journal Chemical Engineering Data, v. 56, p. 1857-1868, 2011.

CERVERA, M. F.; HEINÄMÄKI, J.; RÄSÄNEN, M.; MAUNU, S. L.; KARJALAINEN, M.; COSTA, O. M. N.; COLARTE, A. I.; YLIRUUSI, J. Solid-state characterization of chitosans derived from lobster chitin. Carbohydrate Polymers, v. 58, p. 401-408, 2004.

CRINI, G.; BADOT, P. M. Application of chitosan, a natural aminopolysaccharide, for dye removal from aqueous solutions by adsorption processes using batch studies: A review of recent literature. Progress in Polymer Science, v 33, p. 399-447, 2008.

DOTTO, G. L.; MOURA J. M.; CADAVAL T. R. S.; PINTO L. A. A. Application of chitosan films for the removal of food dyes from aqueous solutions by adsorption. Chemical Engineering Journal, v. 214, p. 816, 2013.

DOTTO, G. L.; SOUZA, V. C.; MOURA, J. M.; MOURA, C. M.; PINTO, L. A. A. Influence of drying techniques on the characteristics of chitosan and the quality of biopolymer films. Drying Technology, v. 29, p. 1784-1791, 2011.

DOTTO, G.L.; PINTO, L.A.A. Adsorption of food dyes acid blue 9 and food yellow 3 onto chitosan: Stirring rate effecte in kinectics and mechanism. Journal Hazardous Materials, v. 187, p. 164-170, 2011.

ELWAKEEL K.Z. Removal of Reactive Black 5 from aqueous solutions using magnetic chitosan resins, Journal of Hazardous Materials, v. 167, p. 383-392, 2009.
FERREIRA， C. O.; NUNES， C. A.; DELGADILLO; LOPES DA SILVA, J. A. Characterization of chitosan whey-protein films at acid pH. Food Research International, v. 42, p. 807-813, 2009.

FUNGARO, D. A.; BRUNO, M. Remoção de azul de metileno de solução aquosa usando zeólitas sintetizadas com amostras de cinzas de carvão diferentes. Química Nova, v. 32, p. 955-959, 2009.

GALED, G.; MIRALLES, B.; PAÑOS, I.; SANTIAGO, A.; HERAS, A. NDeacetylation and depolymerization reactions of chitin/chitosan: Influence of the source of chitin. Carbohydrate Polymers, v. 62, p. 316-320, 2002.

GUIBAL, E.; Interactions of metal ions with chitosan-based sorbents: a review Separation and Purification Technology, v. 38, p. 4374, 2004.

JIANG, X.; CHEN, L.; ZHONG, W. A new linear potenciometric titration method for the determination of desacetylation degree of chitosan. Carbohydrate Polymers, v. 54, p. 457-463, 2003.

KAVITHA, D.; NAMASIVAYAMB， C. Capacity of activated carbon in the removal of acid brilliant blue: Determination of equilibrium and kinetic model parameters. Chemical Engineering Journal, v. 139, p. 453-461, 2008.

KUMAR, M.N.V.R. A review of chitin and chitosan applications. Reactive \& Functional Polymers, v. 46, p. 1-27, 2000.

KUNZ, A.; PERALTA-ZAMOTRA, P.; MORAES, S. G.; DURÁN, N. Novas tendências no tratamento de efluentes têxteis. Química Nova, v. 25, p. 78-82, 2002. 
LIU, Y. Is the free energy change of adsorption correctly calculated?. J. Chemical Engineering Data, v. 54, p. 1981-1985, 2009.

MILONJIC, S. K. A consideration of the correct calculation of thermodynamic parameters of adsorption, Journal of Serbian Chemical Society, v. 72, p. 1363-1367, 2007.

RÊGO, T.V.; CADAVAL JR, T.R.S.; DOTTO, G. L.; PINTO L.A.A., Statistical optimization, interaction analysis and desorption studies for the azo dyes adsorption onto chitosan films. Journal of Colloid and Interface Science, v. 411, p. 27-33, 2013.

RINAUDO, M. Chitin and chitosan: properties and application. Progress Polymer Science, v. 31, p. 603-632, 2006.

ROBERTS, G.A.F., \& DOMSZY, J.G. Determination of the viscometric constants for chitosan. International Journal of Biological Macromolecules, v. 4, p. 374377, 1982.

SILVEIRA NETA, J. J.; SILVA, C. J.; MOREIRA, G. C.; REIS, C.; REIS, E. L. Remoção de corantes Reactive Blue 21 e Direct Red 80 utilizando resíduos de sementes de Mabea fistulifera Mart. como biossorvente. Ambiente e Água, v. 7, p. 104-119, 2012.

TAN, S.C.; KHOR, E.; TAN, T.K.; WONK, S.M. The degree of desacetilation of chitosan: advocating the first derivative UVspectrophotometry methody os determination. Talanta, v. 45, p. 713-719, 1998.

WANG, C. S. Estimation on the intramolecular hydrogen-bonding energies in proteins and peptides by the analytic potential energy function. Journal Molecular Structural, v. 956, p. 38-43, 2010.
WESKA, R.F.; MOURA, J.M.; BATISTA, L.M.; RIZZI, J.; PINTO, L.A.A. Optimization of deacetylation in the production of chitosan from shrimp wastes: Use of response surface methodology. Journal of Food Engineering, v. 80, p. 749-753, 2007.

ZHANG, Z.; ZHANG Z.; MENENDEZ, Y.J.A.; NIU, H.; PENG, J.; ZHANG L.; GUO S. Adsorption isotherms and kinetics of methylene blue on a low-cost adsorbent recovered from a spent catalyst of vinyl acetate synthesis. Applied Surface Science, v. 256, p. 2569-2576, 2010.

\section{AGRADECIMENTOS}

Os autores agradecem a CAPES e ao $\mathrm{CNPq}$ (pelo apoio financeiro). 